\section{Substance of demography}

A GROWING interest in our species is reflected in the recent appearance of several general textbooks on demography. Population: Analysis and Models by L. Henry (Arnold: London, hardback $£ 9.95$; paperback $£ 4.95$ ) adds a valuable member to the company and demonstrates the continuing strength and vitality of the French contribution to these studies. Although in agreement with the translators that no demographer can be without a reading knowledge of French, they are to be congratulated on providing an excellent translation for those whose command of the language is imperfect. This is nevertheless an imposingly technical text, with considerable mathematics, although for the less numerate progress is eased by the usually clear and adequately explained steps. The text introduces a useful and interesting graphical tool, the Lexis diagram; elsewhere, however, more might have been explained by graphical presentation: the treatment, for example, of age-sex pyramids seems to be unnecessarily brief.

M. Henry's approach follows in general the now common 'longitudinal' study (developed by American and British demographers), the examination of data based on generations rather than the more limiting and older "crosssectional' method using only data from periods of a few years. The longitudinal approach is useful in enabling the link between population structure and movement to be clearly developed, and is well suited to the sociological emphasis of demography in the English-speaking world.

The description of the book on the jacket stresses that it covers the conventional substance of demographysource materials, methods of description, nuptiality, fertility, family formation and mortality (note the order!)-but also emphasises the author's attention to migration and its effective integration with population structure. Amid all these goodies, however, one dish seems inadequately prepared. There seems to be a general weakness among demographers that they give little depth to the spatial

- Growing Points in Ethology (Cambridge University : Cambridge), by P. P. G. Bateson and R. A. Hinde, has also been published in paperback, price £5.50. (For review, see Nature 265, 385, 1977.)

- In the review of Environmental Chemistry (Academic: New York and London; Nature 264, 818, 1976), the price was incorrectly quoted. This should read: $\$ 15.95 ; £ 11.30$. elements of population-on p 13, under "Analysis of the Results", two meagre paragraphs on geographical distribution are so trite that they would have been better omitted. But even later in the text, especially when dealing with migration, the spatial element of which is so pronounced, there are statements over which geographers would readily take issue with the author. Regional variation in dynamic patterns seems to go inadequately recognised.

Part II, the final but lesser half of the book, is an introduction to demographic models and, perhaps importantly, a statement as to why models are of value and why they should be considered by demographers. Much of this section is centred round Lotka's theory.

The French version of the UN multilingual demographic dictionary adds a final phrase to the definition of demography that it is a study "from the quantitative point of view"-M. Henry has made just this point.

Methods and Materials of Demography by Shryock et al. (Academic: New York and London, $\$ 16.50$; £9.55) is a condensed version of a twovolume work of the same title originally published by the US Bureau of the Census in 1971 with subsequent later editions. It is now designed primarily as a textbook for courses on various aspects of demography, but it is equally useful to professional workers with occasion to understand or use demographic data for analytic studies.

The author of the abridgement claims to have presented the methodological material in the simplest mathematical form in order to make the text as useful as possible, a claim which even cursory examination of the text supports. For the most part a modest understanding of algebra and statistics will suffice to carry the user through the relevant sections.

Although originally a publication of the US Bureau of the Census, the illustrations and coverage are not solely restricted to American examples, but considerable weight is given to the problems of demographic assessment in the less developed countries. The author does, however, stress that the methods and measurements worked out for the USA are to a considerable degree "culture free" and may serve as well for any other country. In this condensation a necessary choice of inclusions and omissions had to be made. but a balance between formal demography and social and economic demography was sought. In this search, the author has been reasonably successful.

In general the step-by-step illustrations of examples are based on actual figures, although necessarily hypothetical statistics have had to be used in some instances. Where official statistics have been used they have mainly been taken in their form as published, apart from a few instances of simplification. In this condensation, less emphasis has been put on historical development, the recommendations of international organisations and the practices of national statistical agencies, whereas the more technical and mathematical aspects of demographic analysis have been reduced in emphasis.

The book is, however, not without its weaknesses. Certainly chapter 5Population distribution: Geographic areas-leaves many gaps, especially in the discussion of the important aspect of mapping distribution. The range of techniques examined is quite inadequate, and unfortunately some of the less impressive and informative methods are chosen for black-andwhite line diagrams.

Nevertheless this is a fact-packed text invaluable to the do-it-yourself census maker, and brings together much material otherwise diffusely scattered. For any serious course on the principles of demography it should prove a useful if expensive textbook.

R. E. H. Mellor

R. E. H. Mellor is Professor of Geography at the University of Aberdeen, UK.

\section{BOOKS FROM OLEANDER LIBYAN MAMMALS}

\section{Ernst Hufnagl}

A field guide and reference tool with drawings, maps, photographs. Prehistoric mammals, by R. J. G. Savage. Roman mammals, by Lady Brogan. $£ 4.00$ MATHEMATICS OF THE

\section{UNIVERSE}

\section{Philip Francis}

Challenging new concepts in the fields of infinity and relativity. Fully illustrated. $£ 4.95$

\section{THE CAMBRIDGESHIRE} COPROLITE MINING RUSH

Richard Grove

The county's only major industry, which flared up and died down in a few decades at the end of the 19th century. Fully illustrated. $£ 1.20$

\section{CLAY TOBACCO PIPES OF CAMBRIDGESHIRE \\ Robert Flood}

As most pipes can now be dated, with $\mathrm{Mr}$ Flood's detailed makers' lists, within 30 years, his book is a vital contribution to post-mediaeval archaeology. Fully illustrated. $£ 1.20$

\section{announcing}

\section{A DICTIONARY OF}

\section{COMMON FALLACIES}

\section{Philip Ward}

Scientific, medical, mathematical, linguistic, historical and popular fallacies that have plagued the course of progress in knowledge. About December. About $£ 4.95$

Circle No. 40 on Reader Enquiry Form. 